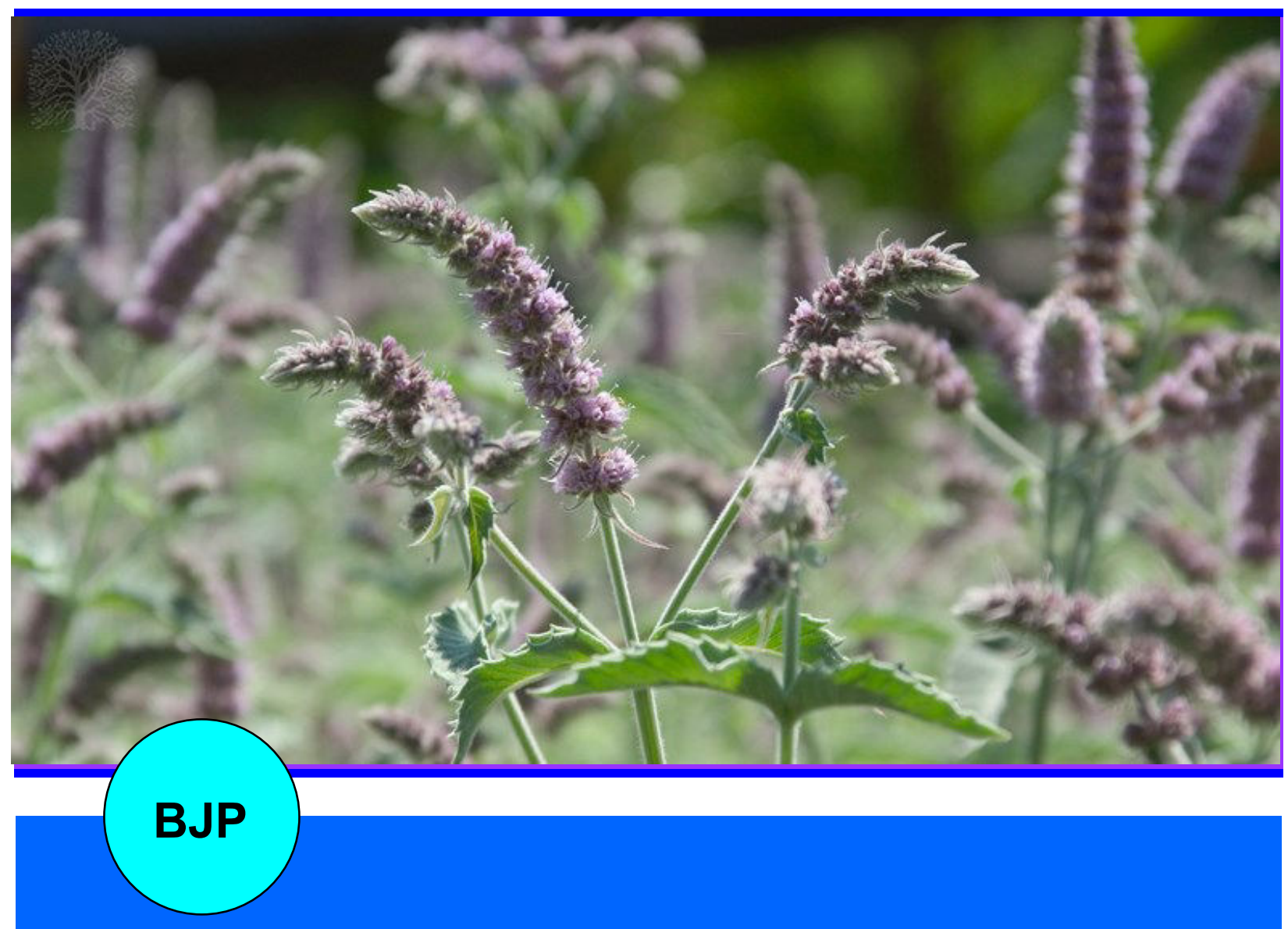

Bangladesh Journal of Pharmacology

Research Article

Antithrombotic activity of Mentha longifolia in animal model 
Abstracted/indexed in Academic Search Complete, Asia Journals Online, Bangladesh Journals Online, Biological Abstracts, BIOSIS Previews, CAB Abstracts, Current Abstracts, Directory of Open Access Journals, EMBASE/Excerpta Medica, Global Health, Google Scholar, HINARI (WHO), International Pharmaceutical Abstracts, Open J-gate, Science Citation Index Expanded, SCOPUS and Social Sciences Citation Index;

ISSN: $1991-0088$

\title{
Antithrombotic activity of Mentha longifolia in animal model
}

\author{
Alamgeer, Qurat ul Ain, Umme Habiba Hasan and Hira Asif \\ Laboratory of Cardiovascular Research and Integrative Pharmacology, University of Sargodha, Sargodha 40100 ,
} Pakistan.

\begin{tabular}{|lr|}
\hline Article Info & \\
\hline Received: & 16 July 2017 \\
Accepted: & 5 February 2018 \\
Available Online: & 5 March 2018 \\
DOI: 10.3329/bjp.v13i1.33243 \\
\\
\\
\\
\\
Cite this article: \\
Alamgeer, Ain QU, Hassan UH, Asif \\
H. Antithrombotic activity of Mentha \\
longifolia in animal model. Bangladesh \\
J Pharmacol. 2018; 13: 67-73.
\end{tabular}

\begin{abstract}
The present research work was conducted to appraise the antithrombotic activity of Mentha longifolia using in vitro and in vivo experiments. Aqueous methanolic (70:30) extract produced significant $(\mathrm{p}<0.01-0.001)$ and dosedependent increase in in vitro blood clotting time, bleeding time, prothrombin time and activated partial thromboplastin level with maximum effect at highest concentration. While in in vivo experiment, aqueous methanol extract showed noteworthy $(\mathrm{p}<0.01-0.001)$ prolongation in bleeding time and clotting time after 30, 60 and $90 \mathrm{~min}$ of administration except for $25 \mathrm{mg} / \mathrm{kg}$ at $30 \mathrm{~min}$ which is non-significant. Moreover, plant extract exhibited considerable increase $(p<0.1-0.001)$ in bleeding time, clotting time, prothrombin time as well as activated partial thromboplastin time in rabbits after seven days of treatment. Additionally, HPLC analysis of M. longifolia aqueous methanolic extract illustrated the presence of various valuable phytoconstituents. In a nutshell, M. longifolia possesses potential antithrombotic activity and hence systematically proved to be beneficial in patients with vascular diseases.
\end{abstract}

\section{Introduction}

Thrombosis is a multifaceted physiological process associated with pathogenesis of ischemic brain diseases and ischemic heart diseases (Rajput et al., 2012). In many developed countries, thromboembolic complications such as heart attack, deep vein thrombosis, pulmonary emboli, and strokes are the major causes of morbidity and mortality (Kumar et al., 2011). Recent antithrombotic agents consist of anticoagulants, thrombolytics and antiplatelets which reduce blood clotting by dissolving previously developed clot or preventing new clot formation. Nevertheless, these drugs are allied with severe adverse effects like bleeding, thrombocytopenia, drug-drug interactions, allergic reactions and cerebral hemorrhage. Reocclusion may occur in some cases and increase the mortality and morbidity associated with thrombotic complications (Albuquerque et al., 2004). Moreover, direct thrombin and factor Xa inhibitors are the new drugs as alternative to vitamin $\mathrm{K}$ antagonists for stroke prevention in atrial fibrillation but associated with various clinical limitations such as unpredictable dose-response relationship and need of intense monito-ring. Owing to above mentioned shortcomings, there is need to seek out newer drugs with safety, effectiveness and lack of severe toxicity (Moll et al., 2002).

Medicinal plants such as Triclisia dictyophylla, Dictyota menstrualis, Berberis calliobotrys, Orbignya phalerata have shown to have antithrombotic effects (Ajugwo and Ezimah, 2013; Albuquerque et al., 2004; Alamgeer et al., 2016; Azevedo et al., 2007).

Mentha longifolia L. belonging to Lamiaceae family is a perennial herb and locally known as Junglee Pudina in Pakistan (Shah et al., 2009; Bertoli et al., 2011). Traditionally it is also used to treat rheumatism, neuralgia, gall stone, cardiovascular problems, gastric disorders, bladder stone, jaundice, toothache, dyspnea, sedative, insect repellent and headache (Haq et al., 2011; Naghibi 
et al., 2010). Hence, the current study was designed to corroborate the antithrombotic activity of $M$. longifolia to be used effectively in the cardiovascular diseases.

\section{Materials and Methods}

\section{Experimental animals}

Healthy rabbits of either sex weighing 1.0-1.5 kg were used in this study. Animals were fed with seasonal green leafy vegetables and Alfa Alfa leaves with tap water ad libitum. They were housed under standard laboratory conditions of $21 \pm 2^{\circ} \mathrm{C}$, relative humidity $55 \%$ and 12 hours light/dark cycle. The in vitro tests were performed on blood taken from the rabbits.

\section{Chemicals}

Methanol, (Merck®, Germany), heparin (Leo Pharmaceuticals ${ }^{\circledR}$, Denmark), prothrombin reagent, (Macc and Rains Pharmaceuticals (Pvt.) Ltd. Pakistan), activated partial thromboplastin reagent (Mac and Rains Pharmaceuticals (Pvt.) Ltd. Pakistan), trisodium citrate, (Sigma Chemicals, USA) and EDTA (Sigma Chemicals, USA) were purchased.

\section{Plant collection and extraction}

Aerial-parts of the M. longifolia were collected from a village of District Gilgit, Shikyote, from Gilgit-Baltistan, Pakistan and authenticated by Dr. Sheer Wali Khan, taxonomist, Department of Botany, Karakuram International University, Gilgit-Baltistan. The aqueous methanol extract was prepared by cold maceration technique by soaking finley powdered plant material in a mixture of aqueous-methanol (70:30) at room temperature for 3 days followed by filtration. Finally, filterate was evaporated using rotary evaporator and then dried by lyophilizer (Gilani et al., 2005).

\section{In vitro experiments on rabbit blood}

\section{Clotting time}

In vitro anticoagulant activity of $M$. longifolia on blood clotting was determined by following the method as described by Nwaehujor et al. (2013). In brief, $1.0 \mathrm{~mL}$ of blood was drawn from the marginal vein of rabbit's ear and then added in $0.2 \mathrm{~mL}$ of $2.5,5$ and $10 \% \mathrm{w} / \mathrm{v}$ solutions of $M$. longifolia extract in different test tubes respectively afterward incubation at $37^{\circ} \mathrm{C}$. Clotting time of the blood was recorded. Distilled water and blood were used as control for baseline clotting time.

\section{Thrombolytic activity}

The extract solution of varying concentrations 10, 20, 40 and $80 \mathrm{mg} / \mathrm{mL}$ were prepared. Then $0.5 \mathrm{~mL}$ of blood from the jugular vein of the rabbit was transferred in the previously weighed and sterilized eppendorff tubes after that incubated at $37^{\circ} \mathrm{C}$ for the period of $45 \mathrm{~min}$ to clot. Afterwards the serum was completely removed from the tube and weighed the tube again. $100 \mu \mathrm{L}$ of test solution was added to each Eppendorff tube containing pre-weighed blood clot. In negative control tube, distilled water was added instead of the extract solution. All the tubes were again incubated for $90 \mathrm{~min}$ at $37^{\circ} \mathrm{C}$ and monitored for clot lysis (Alamgeer et al., 2016). Subsequent to incubation, the released fluid was removed completely and the tube was weighed over again. The percentage of clot lysis was expressed as the difference in weight taken before and after clot lysis and calculated by the following formula:

$\%$ lysis $=$ Weight of released clot $/$ Weight of clot $\times 100$

Where, weight of released clot $=$ weight of clot before lysis weight of clot after lysis

Determination of in vitro prothrombin time and activated partial thromboplastin time

Trisodium citrate was added in all the centrifuge tubes followed by the addition of $3 \mathrm{~mL}$ of blood sample from the rabbit $(n=5)$ and subjected to centrifugation at 3,000 rpm for $5 \mathrm{~min}$. The plasma was separated using micropipette into the eppendorff tubes. $250 \mathrm{uL}$ of the $M$. longifolia extract solution of different concentrations 2.5, 5 and $10 \%$ was added into the eppendorff tubes separately. To determine prothrombin time, samples were incubated at $37^{\circ} \mathrm{C}$ for $5 \mathrm{~min}$ afterward $200 \mathrm{uL}$ of prothrombin time reagent was added to $100 \mathrm{uL}$ of test plasma and clotting time was measured as prothrombin time. Moreover, for appraisal of activated partial thromboplastin time, $100 \mathrm{uL}$ of activated partial thromboplastin reagent was added to $100 \mathrm{uL}$ of test plasma (platelet poor plasma + plant extract of various concentration) and the mixture was incubated for $1 \mathrm{~min}$ after which $100 \mathrm{uL}$ calcium chloride $(25 \mathrm{mmol})$ was added and again incubated for $15 \mathrm{sec}$. Then clotting time was recorded as activated partial thromboplastin time (Alamgeer et al., 2016; Jagtap et al., 2012).

Determination of in vivo bleeding time and clotting time

In vivo bleeding time was appraised by following the procedure of Nwaehujor et al. (2013) with minor modification. Rabbits were segregated into four groups of five rabbits in each group. Aqueous methanol extract was given at 25,50 , and $100 \mathrm{mg} / \mathrm{kg}$ dose levels to Group I, II and III respectively. Group IV was taken as control group. Then marginal ear vein was pricked after intervals of $0,30,60$, and $90 \mathrm{~min}$ and after every five seconds filter paper was used to check bleeding on scarred ear vein. Moreover, capillary tube method was used to determine the effect of M. longifolia aqueous methanolic extract on clotting time. Extract was administered to four groups of rabbits of five rabbits in each group. Group I was treated with $25 \mathrm{mg} / \mathrm{kg}$, Group II was treated with $50 \mathrm{mg} / \mathrm{kg}$ whereas $100 \mathrm{mg} / \mathrm{kg}$ was 
administered to Group III. One group was served as control. After piercing marginal ear vein, clotting time was noted after 0, 30, 60 and $90 \mathrm{~min}$ of dose administration. Blood was collected from pierced vein with the help of capillary tube by horizontally placing it. After every $30 \mathrm{sec}$, capillary tube was broken till the coagulated blood was shown in the form of thread.

Assessment of coagulation parameters after seven days of in vivo treatment

In determination of anticoagulant activity, seven day treatment was done with aqueous methanolic extract of M. longifolia by following the method of Alamgeer et al. (2016) with some modifications. Rabbits were divided into four groups of five rabbits in each group. First group was taken as control group whereas remaining groups were given different doses (25,50 and $100 \mathrm{mg} /$ $\mathrm{kg}$ ) of aqueous methanolic extract of M. longifolia for a week. After seven days of treatment effect on clotting time was determined by capillary tube method and bleeding time was determined by filter paper method as described by Elg et al. (2001). Moreover, at day 7 blood sample was collected from each rabbit of each group and PT and APTT tests were performed (Alamgeer et al., 2016).

\section{Phytochemical investigation by using HPLC technique}

The sample was prepared by the method of Tokusoglu (2003) with minor modification. The sample was prepared by mixing $16 \mathrm{~mL}$ of distilled water with $24 \mathrm{~mL}$ methanol and $50 \mathrm{mg}$ plant extract. Then $10 \mathrm{~mL}$ of $6 \mathrm{M}$ $\mathrm{HCl}$ was mixed. The mixture was kept in an oven at $95^{\circ}$ $\mathrm{C}$ for 2 hours to isolate aglycones of flavonol (glyco- sides) and then it was filtered through microfilter before injecting into the HPLC. An HPLC analysis was performed using HPLC model LC-10A fitted with SCL10A system control unit, rheodyne injector, two LC-10 AT pumps, CTO-10A column oven, SPD-10A UVVisible detector and data acquisition class LC-10 software. Then filtered sample $(20 \mu \mathrm{L})$ was injected into an analytical Shim-Pack CLC-ODS reverse phase (C-18) column $(25 \mathrm{~cm} \times 4.6 \mathrm{~mm} ; 5 \mu \mathrm{m}$ particle size $)$. Solvent $\mathrm{A}$ $\left(\mathrm{H}_{2} \mathrm{O}\right.$ : acetic acid- 94:6, pH=2.27) and solvent $\mathrm{B}$ (acetonoitrile $100 \%$ ) were used. Graded elution of mobile phase was used to perform chromatographic separation (mixture of solvent A and solvent B (50:50 v/v), which was filtered using $0.45 \mu \mathrm{m}$ membrane under vacuum before use) at a flow rate of $1 \mathrm{~mL} / \mathrm{min}$ at $30^{\circ} \mathrm{C}$. Detection was performed at a wavelength of $280 \mathrm{~nm}$ (Sultana, 2008).

\section{Statistical analysis}

Results were expressed as mean \pm SEM. Statistical analysis was performed by One-way analysis of variance (ANOVA) with post test Dunnet's. $p<0.05$ was considered as statistically significant.

\section{Results}

\section{Effect on in vitro blood clotting time}

The aqueous methanol extract produced significant $(\mathrm{p}<0.001)$ and dose-dependent $(2.5,5$ and $10 \%)$ increase in blood clotting time with maximum effect at $10 \%$ extract solution (Figure 1A).

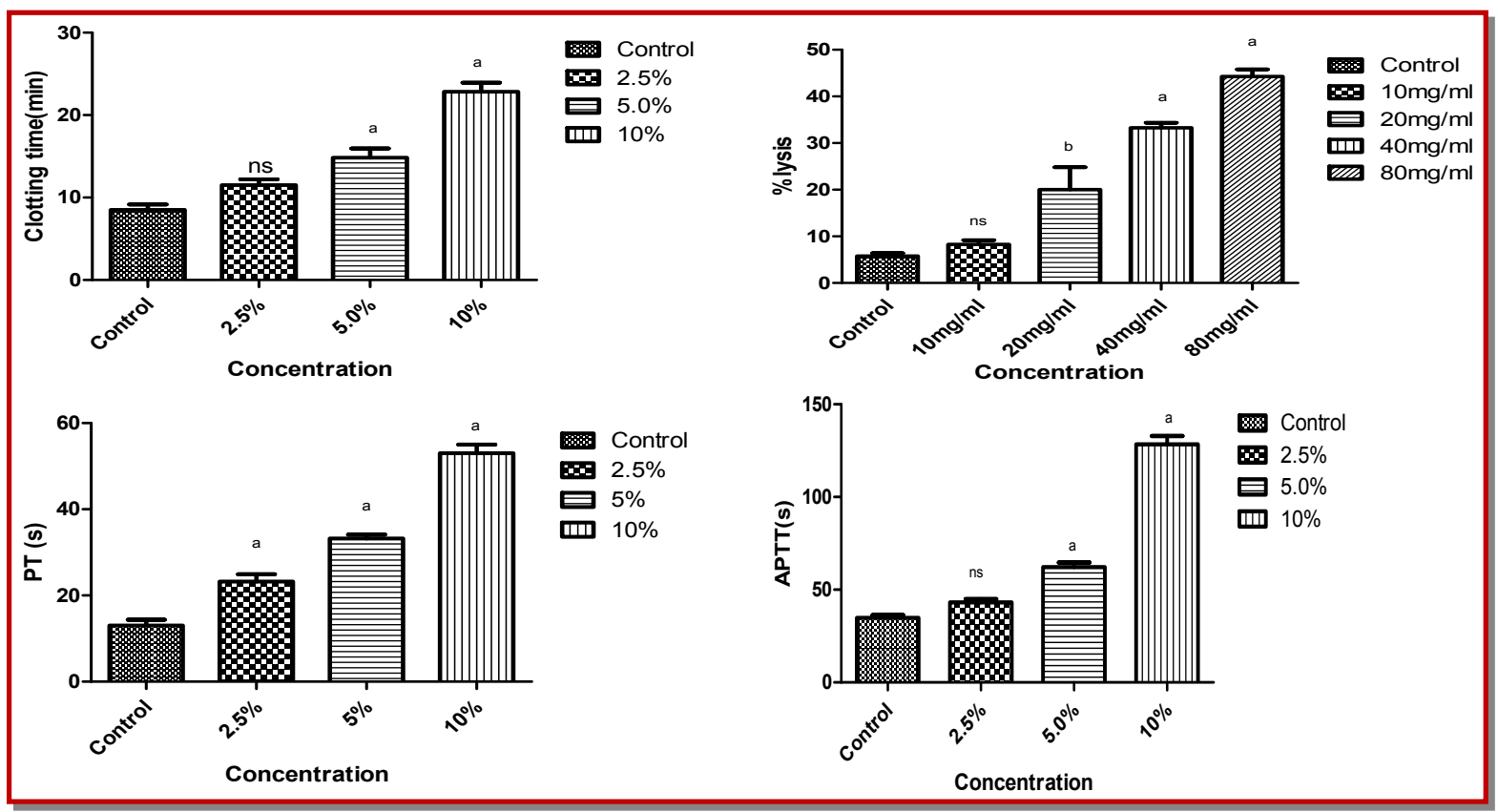

Figure 1: Effect of aqueous methanolic extract of M. longifolia on clotting time (A), clot lysis (B), prothrombin time (C), and activated partial thromboplastin time (D) of rabbit blood; ns = non significant and ${ }^{a} p<0.001,{ }^{b} p<0.01$ 


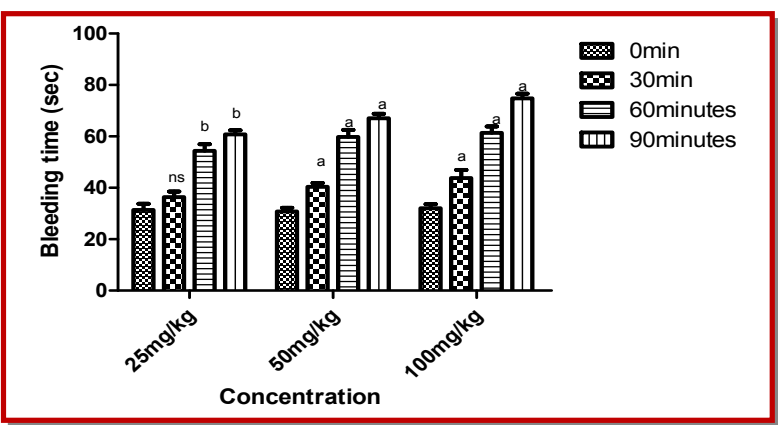

Figure 2: Effects of aqueous methanolic extract of M. longifolia on bleeding time of rabbit. Where, nsnon significant, ${ }^{b} p<0.01$ and ${ }^{\mathrm{p}}<0.001$

\section{Effect on in vitro thrombolytic activity}

The methanolic $(70 \%)$ extract of $M$. longifolia revealed noteworthy increase $(\mathrm{p}<0.01-0.001)$ in clot lysis at 10,20 , 40 and $80 \mathrm{mg} / \mathrm{mL}$ with maximum thrombolytic activity at $80 \mathrm{mg} / \mathrm{mL}$ (Figure $1 \mathrm{~B}$ ).

Effect on in vitro prothrombin time and activated partial thromboplastin time

Different concentrations of plant extract $(2.5,5$ and 10\%) exhibited considerable $(\mathrm{p}<0.001)$ increase in prothrombin time and activated partial thromboplastin time on concentration reliant manner (Figure 1C, D).

\section{Effect of plant extract on in vivo bleeding time and clotting time}

Plant extract produced substantial $(\mathrm{p}<0.01-0.001)$ and dose-dependent (25, 50 and $100 \mathrm{mg} / \mathrm{kg}$ ) increase in bleeding and clotting time after 30, 60 and $90 \mathrm{~min}$ of administration except for $25 \mathrm{mg} / \mathrm{kg}$ at $30 \mathrm{~min}$ which was non-significant (Figure 2).

Effect on various coagulation parameters after seven days treatment of $M$. longifolia extract in rabbit

The aqueous methanolic extract of $M$. longifolia significantly $(\mathrm{p}<0.1-0.001)$ and dose dependently $(25,50$ and $100 \mathrm{mg} / \mathrm{kg}$ ) increased the bleeding time, clotting time, prothrombin time and activated partial thromboplastin time in rabbits (Table I).
HPLC analysis of M. longifolia aqueous methanolic extract

The HPLC analysis of the M. longifolia aqueous methanolic extract showed the presence of quercitin, gallic acid, caffeic acid, p-coumaric acid, m-coumaric acid, ferulic acid and trans-4-hydroxy-3-methoxy cinnamic acid (Figure 3).

\section{Discussion}

From current findings, it has been avowed that the aqueous methanolic extract significantly increased the bleeding time, clotting time, prothrombin time and activated partial thromboplastin time. Although, exact mechanism of anticoagulant activity is not known but heparin, chelating agents and vitamin $\mathrm{K}$ antagonists exert their effects by acting at various steps in blood coagulation pathways. Moreover, increase in bleeding time might be considered owing to low platelet count or antilipid peroxidation effect as lipid peroxides cause platelet aggregation (Gadi et al., 2009). In effect inhibition of platelet aggregation increase the bleeding time in animals (De Caterina et al., 1994) as declared from the findings of current analysis.

Clotting time is another major determinant of intrinsic pathway (Dapper et al., 2007). It involves various intrinsic clotting factors e.g.; I, II, V, VIII, IX, X, XI and XII, and any defect in any of these factors may increase or decrease the blood clotting time (Weremfo et al., 2011). These clotting factors are proteinic in nature and are present in resting state in blood pool and when the vessels become damaged they come into action and so play their part in coagulation cascade (Alesci et al., 2009). Aqueous methanloic extract delayed blood clotting as corroborated by results of in vitro and in vivo studies. As in coagulopathy the most reliable test is prothrombin time test (Hinchcliff et al., 2013; Furlanello et al., 2006). Prothrombin time and activated partial thromboplastin time are the tests that differentiate between the changes in extrinsic pathway or intrinsic pathway of blood clotting. Intrinsic clotting factors are assessed by activated partial thromboplastin time and

\begin{tabular}{|c|c|c|c|c|}
\hline \multicolumn{5}{|c|}{ Table I } \\
\hline \multicolumn{5}{|c|}{ Effect of aqueous methanolic extract on different blood coagulation parameters after seven days of treatment } \\
\hline \multirow[t]{2}{*}{ Blood parameters } & \multicolumn{4}{|c|}{ Dose } \\
\hline & Control & $25 \mathrm{mg} / \mathrm{kg}$ & $50 \mathrm{mg} / \mathrm{kg}$ & $100 \mathrm{mg} / \mathrm{kg}$ \\
\hline Bleeding time (sec) & $31.4 \pm 2.4$ & $70.6 \pm 3.5^{\mathrm{a}}$ & $87.8 \pm 1.9^{a}$ & $95.4 \pm 1.9^{a}$ \\
\hline Clotting time (sec) & $186.0 \pm 3.6$ & $201.6 \pm 8.1^{\mathrm{ns}}$ & $261.2 \pm 3.0^{\mathrm{a}}$ & $311.4 \pm 3.5^{\mathrm{a}}$ \\
\hline Prothrombin time (sec) & $11.2 \pm 1.1$ & $19.4 \pm 1.9 c$ & $27.0 \pm 2.6^{\mathrm{a}}$ & $33.0 \pm 1.6^{\mathrm{a}}$ \\
\hline Activated partial thromboplastin time (sec) & $25.6 \pm 1.8$ & $42.4 \pm 4.4^{\mathrm{b}}$ & $54.8 \pm 1.5^{\mathrm{a}}$ & $65.8 \pm 2.1^{\mathrm{a}}$ \\
\hline
\end{tabular}




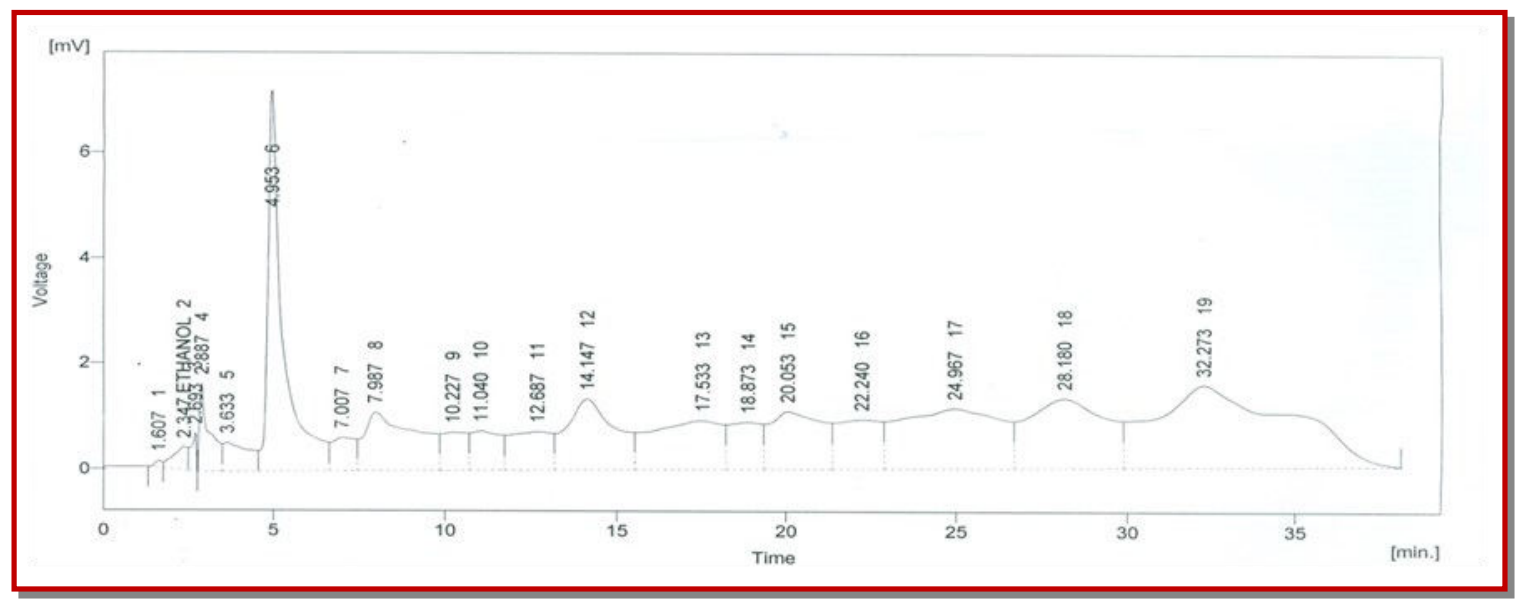

Figure 3: HPLC analysis of aqueous methanolic extract of Mentha longifolia

any defect in clotting factors (VIII, IX, XI, XII, and V) and Willebrand's factor is reflected by increase in APTT and decrease in PT reflects abnormalities in coagulation factors V, VII and factor X (Vogel, 2006). Though these two factors are also affected by inhibitors of coagulation factors along with inhibition of phospholipid and $\mathrm{Ca}^{++}$ activity (Azevedo et al., 2007). In view of the fact that plant extract delayed both in vitro and in vivo prothrombin time and activated partial thromboplastin time as declared in results of present study.

It is previously investigated that coumarins are involved to decrease the coagulation extent (Pochet et al., 2004). Likewise M. longifolia also contains coumarin as important part of its active constituents (Shah et al., 2010) as reported in HPLC results. Coumarin is the major organic compound in phytochemicals that is said to have particular anticoagulant activity (Morton, 1992) and its derivatives are reported to increase bleeding time in animals. In liver, synthesis of some clotting factors II, VII, IX and X depends on the presence of vitamin $\mathrm{k}$ where inadedione groups and coumarins present in anticoagulant drugs antagonize the synthesis of coagulant proteins and hence interferes with the formation of blood clot (Dejana et al., 1979). Furthermore these constituents interfere the metabolism of vitamin $\mathrm{K}$ and so stop the synthesis of vitamin $\mathrm{K}$ dependent coagulation factors (Meyer et al., 1992; Radositis et al., 1997). Some researchers have reported that thrombolytic action of plants may be attributable to presence of tannins, saponins and alkaloids. Seeing that C. xanthocarpa has shown inhibition of platelet aggregation on account of terpenes, saponins, tannins and flavonoids (Klafke et al., 2010) and flavonoids and coumarins are responsible for antithrombotic activity of Peucedanum grande (Nijveldt et al., 2001; Heim et al., 2002). In addition, numerous earlier studies advocate the presence of flavonoids (quercitin, quercitrin, myricetin and rutin), tannins and phenolic compounds in plants having antithrombotic activity (Schmeda-
Hirschmann, 1995; Markman et al., 2004; Hsu et al., 2008). It is hypothesized that plant exert thrombolytic activity which might be due to the presence of some flavonoids that inhibit platelet aggregation by binding to throm-boxane $\mathrm{A}_{2}$ receptors (Guerrero et al., 2005; Han et al., 2012).

\section{Conclusion}

Flavonoids, coumarins and other phytoconstituents may participate in the thrombolytic action of $M$. longifolia as stated in HPLC analysis.

\section{Ethical Issue}

The study protocol was approved by the Institutional Animal Ethics Committee, Faculty of Pharmacy, University of Sargodha. All experiments are designed in accordance with the standard procedures of National Research Council (NRC, 1996).

\section{Conflict of Interest}

The authors have no conflicts of interest.

\section{Acknowledgement}

All authors are grateful to the University of Sargodha for providing some financial support for this study.

\section{References}

Ajugwo AO, Ezimah AC. In vivo studies of anticoagulation activity of Triclisia dictyophylla using albino Wistar rats. J Pharm Pharm Sci. 2013; 2: 37-40.

Albuquerque I, Queiroz K, Alves L, Santos E, Leite E, Rocha H. 
Heterofucans from Dictyota menstrualis have anticoagulant activity. Braz J Med Biol Res. 2004; 37: 167-71.

Alamgeer, Asif H, Rasool S. Antithrombotic potential of Berberis calliobotrys extract. Bangladesh J Pharmacol. 2016; 11: 776-83.

Alesci S, Borggrefe M, Dempfle CE. Effect of freezing method and storage at- 20 and $70^{\circ} \mathrm{C}$ on prothrombin time, aPTT and plasma fibrinogen levels. Thromb Res. 2009; 124: 121-26.

Azevedo APS, Farias JC, Costa GC, Ferreira SC, Aragao-Filho, WC, Sousa PR, Pinheiro MT, Maciel MC, Silva LA, Lopes AS. Antithrombotic effect of chronic oral treatment with Orbignya phalerata Mart. J Ethnopharmacol. 2007; 111: 155-59.

Bertoli A, Leonardi M, Krzyzanowska J, Oleszek W, Pistelli L. Mentha longifolia in vitro cultures as safe source of flavouring ingredients. Acta Biochim Pol. 2011; 58: 581-87.

Capstick T, Henry M. Efficacy of thrombolytic agents in the treatment of pulmonary embolism. Eur Respir J. 2005; 26: 864 -74 .

Dapper D, Achinike P, Gwotmut M. The effects of Aloe vera [gel] on clotting time, prothrombin time and plasma fibrinogen concentration in albino Wistar rats. Port Harcourt Med J. 2007; 2: 56-60.

De Caterina R, Lanza M, Manca G, Strata GB, Maffei S, Salvatore L. Bleeding time and bleeding: An analysis of the relationship of the bleeding time test with parameters of surgical bleeding. Blood 1994; 84: 3363-70.

Dejana E, Callioni A, Quintana A, de Gaetano G. Bleeding time in laboratory animals. II-A comparison of different assay conditions in rats. Thromb Res. 1979; 15: 191-97.

Elg M, Carlsson S, Gustafsson D. Effects of agents, used to treat bleeding disorders, on bleeding time prolonged by a very high dose of a direct thrombin inhibitor in anesthesized rats and rabbits. Thromb Res. 2001; 101: 11.

Furlanello T, Caldin M, Stocco A, Tudone E, Tranquillo V, Lubas G, Solano-Gallego L. Stability of stored canine plasma for hemostasis testing. Vet Clin Pathol. 2006; 35: 204-07.

Gadi D, Bnouham M, Aziz M, Ziyyat A, Legssyer A, Legrand C, Lafeve FF, Mekhfi H. Parsley extract inhibits in vitro and ex vivo platelet aggregation and prolongs bleeding time in rats. J Ethnopharmacol. 2009; 125: 170-74.

Gilani AH, Shah AJ, Ghayur MN, Majeed K. Pharmacological basis for the use of turmeric in gastrointestinal and respiratory disorders. Life Sci. 2005; 76: 3089-105.

Guerrero J, Lozano M, Castillo J, Benavente-garcía O, Vicente $\mathrm{V}$, Rivera J. Flavonoids inhibit platelet function through binding to the thromboxane A2 receptor. J Thromb Haemost. 2005; 3: 369-76.

Han N, Gu Y, Ye C, Cao Y, Liu Z, Yin J. Antithrombotic activity of fractions and components obtained from raspberry leaves (Rubus chingii). Food Chem. 2012; 132: 18185.

Haq F, Ahmad H, Alam M. Traditional uses of medicinal plants of Nandiar Khuwarr catchment (District Battagram). Pakistan J Med Plants Res. 2011; 5: 39-48.
Heim KE, Tagliaferro AR, Bobilya DJ. Flavonoid anti-oxidants: Chemistry, metabolism and structure-activity relationships. J Nutr Biochem. 2002; 13: 572-84.

Hinchcliff KW, Kaneps AJ, Geor RJ. Equine sports medicine and surgery, Elsevier Health Sciences, 2013.

Hsu CL, Yen GC. Phenolic compounds: Evidence for inhibitory effects against obesity and their underlying molecular signaling mechanisms. Mol Nutr Food Res. 2008; 52: 53-61.

Jagtap A, Sancheti JS, Phadke AS. Antiplatelet and antithrombotic activity of ethanolic extract of Emblica ribes. Int J Res Phytochem Pharmacol. 2012; 2: 150-56.

Klafke JZ, da Silva MA, Panigas TF, Belli KC, de Oliveira MF, Barichello MM, Rigo FK, Rossato MF, dos Santos ARS, Pizzolatti MG. Effects of Campomanesia xanthocarpa on biochemical, hematological and oxidative stress parameters in hypercholesterolemic patients. J Ethnopharmacol. 2010; 127: 299-305.

Kumar S, Joseph L, George M, Sharma A. A review on anticoagulant/antithrombotic activity of natural plants used in traditional medicine. Int J Pharm Sci Rev Res. 2011; 8: 7074 .

Liu S, Manson JE, Lee IM, Cole SR, Hennekens $\mathrm{CH}$, Willett WC, Buring JE. Fruit and vegetable intake and risk of cardiovascular disease: The Women's Health Study. Am J Clin Nutr. 2000; 72: 922-28.

Markman BEO, Bacchi EM, Kato ETM. Antiulcerogenic effects of Campomanesia xanthocarpa. J Ethnopharmacol. 2004; 94: 5557.

Meyer DJ, Coles EH, Rich LJ. Veterinary laboratory medicine: Interpretation and diagnosis, 1992.

Moll S, Roberts HR. Overview of anticoagulant drugs for the future. Seminars in hematology, Elsevier, 2002.

Morton JF. The ocean-going noni, or Indian mulberry (Morinda citrifolia, Rubiaceae) and some of its "colorful" relatives. Econ Bot. 1992; 46: 241-56.

Naghibi F, Mosaddegh M, Mohammadi Motamed M, Ghorbani A. Labiatae family in folk medicine in Iran: From ethnobotany to pharmacology. Iran J Pharm Res. 2010; 4: 63-79.

Nijveldt RJ, Van Nood E, Van Hoorn DE, Boelens PG, Van Norren K, Van Leeuwen PA. Flavonoids: A review of probable mechanisms of action and potential applications. Am J Clin Nutr. 2001; 74: 418-25.

Nwaehujor CO, Ode Julius O, Nwinyi Florence C, Madubuike Stella A. Anticoagulant and anti-oxidant activities of dracaena arborea leaves (Wild.) link. Am J Biomed Res. 2013; 1: 86-92.

Pochet L, Frederick R, Masereel B. Coumarin and isocoumarin as serine protease inhibitors. Curr Pharm Des. 2004; 10: 378196.

Prasad S, Kashyap RS, Deopujari JY, Purohit HJ, Taori GM, Daginawala HF. Effect of fagonia arabica (Dhamasa) on in vitro thrombolysis. BMC Complem Altern M. 2007; 7: 36.

Raaof A, Al-Naqqash ZAE, Jawad ALM, Muhsan SM. Evalua- 
tion of the activity of crude alkaloids extracts of Zingiber officinale Roscoe, Thymus vulgaris L. and Acacia arabica L. as coagulant agent in lab mice. J Biomed Biotechnol. 2013; 1: 1116.

Radositis O, Blood D, Gay C. Veterinary medicine a textbook of the diseases of cattle, sheep, pigs, goats and horses. 1997.

Rajput MA, Khan RA, Qazi N, Feroz Z. Effect of methanol extract of ajwain (Trachyspermum ammi L) on blood coagulation in rats. JLUMHS. 2012; 11: 105-08.

Schmeda-Hirschmann G. Flavonoids from calycorectes, campomanesia, eugenia and hexachlamys species. Fitoterapia 1995; 66: 373-74

Shah AJ, Bhulani NN, Khan SH, Gilani AH. Calcium channel blocking activity of Mentha longifolia L. explains its medicinal use in diarrhoea and gut spasm. Phytother Res. 2010; 24: 1392-97.
Sultana BFA, Asi MR, Chatha SAS. Anti-oxidant potential of extracts from different agro wastes: Stabilization of corn oil. Grasas Y Aceites. 2008; 59: 17.

Tapsell LC, Hemphill I, Cobiac L, Sullivan DR, Fenech M, Patch CS, Roodenrys S, Keogh JB, Clifton PM, Williams PG. Health benefits of herbs and spices: The past, the present, the future. Med J Aust. 2006; 185: S4-24.

Tokusoglu O, Unal MK, Yildirum Z. HPLC-UV and GC-MS characterization of the flavonol aglycons quercetin, kaempferol and myrecetin in tomato and tomato pastes and other tomato-based products. Acta Chromatogr. 2003; 13: 12.

Wardlaw JM, del Zoppo GJ, Yamaguchi T, Berge E. Thrombolysis for acute ischaemic stroke. Cochrane Database Syst Rev. 2009; 4: CD000213.

Weremfo A, Adinortey M, Pappoe A. Haemostatic effect of the stem juice of Musa paradisiaca L.(Musaceae) in guinea pigs. Adv Biol Res. 2011; 5: 190-92. 